\title{
The role of the cholinergic nervous system in memory consolidation
}

\author{
HERBERT WEINGARTNER, NATRAJ SITARAM, and J. CHRISTIAN GILLIN \\ National Institute of Mental Health, Bethesda, Maryland 20014
}

\begin{abstract}
Arecoline hydrobromide (2 mg IV), a cholinergic agonist, facilitates the recall of words that have been organized and encoded immediately prior to drug treatment. While the number of groups of words and the total number of words recalled are increased, words within recalled structures are unaffected by cholinergic stimulation. The findings define a role of the cholinergic nervous system in memory consolidation.
\end{abstract}

Recent research efforts have begun to successfully define some of the psychobiological features of cognitive processes in man. Some drug-induced changes in brain neurochemical activity and a variety of neuropathological states have been associated with both qualitative and quantitative changes in the storage, encoding, and retrieval of information (Caine, Ebert, \& Weingartner, 1977; Weingartner, 1978). However, the specificity of the psychological and biological relationships that determine aspects of cognition remain poorly understood, since (1) none of the cognitive models that are currently in vogue present a sufficiently detailed picture of component cognitive processes, and (2) the manner in which neurobiological events are defined and how these are associated with cognitive processes are described only in the most general terms. Nevertheless, through the use of well defined clinical findings, as well as through studies utilizing neuropharmacological tools with relatively discrete effects on brain, there begins to emerge the possibility of a detailed and specific psychobiology of cognition (Alpern \& Jackson, 1978; Rose, Hambley, \& Haywood, 1976).

In this study, we explored how changes in one neurotransmitter system, the cholinergic central nervous system (CNS), might affect the formation of trace events in memory. The cholinergic CNS appears to play an important role in cognition and learning, but most of this research has been based un extrapolation from animal learning studies (Davis, Thomas, \& Adams, 1971; Deutsch, 1971; Khavari, 1971; Moss \& Deutsch, 1975; Puerto, Molina, Rogers, \& Moss, 1976; Squire, 1970; Stanes \& Brown, 1976). For example, animal learning studies have shown that biological treatments that increase cholinergic activity enhance characteristics of learning, while treatments that block the action of, for example, acetylcholine, interfere with learning (Moss \& Deutsch, 1975; Puerto et al., 1976; Stanes \& Brown, 1976; Stein, Beluzzi, \& Wise, 1975). Other research has also implicated the specific role of cholinergic substances in some areas of the CNS known to be anatomically involved in memory trace formation (Matthies, Rauca, \&
Liebmann, 1974). Arecoline, the drug used to stimulate cholinergic activity in this study, (1) mimics the effect of acetylcholine at the muscannic cholinergic receptor, (2) passes the blood brain barrier, and (3) is unaffected by cholinesterase, the enzyme that normally hydrolizes acetylcholine at the synapse. In order to prevent peripheral muscarinic side effects, methscopolamine, an anticholinergic agent, was administered prior to arecoline treatment. Methscopolamine, a peripherally acting anticholinergic drug, does not cross the blood brain barrier. It has also been shown to not affect learning and memory functions (Drachman \& Leavitt, 1974; Sitaram, Weingartner, \& Gillin, 1978).

In this study, we tested whether drug-induced increases in cholinergic functions might produce an enhancement in some components of memory trace consolidation and retrieval when drug treatment is introduced just after processing (organizing) sets of words. The experimental strategy for effecting changes in memory trace formation was more typical of animal rather than human learning studies; that is, treatments that might alter learning were introduced postlearning or after information had been processed, rather than just before or at the time of information storage. The aspects of learning that represent the focal cognitive response in this study pitted the learning of clusters of organized items or higher order memory units against the learning of the more unitary responses, such as individual items, that are typically of interest in animal learning studies.

\section{METHOD}

Subjects were paid normal volunteers $(n=8,5$ males and 3 females; mean age $=24.3$ years, ranging from 19 to 26 years) who gave their informed consent to participate in the study.

During an initial practice session, subjects were familiarized with the cognition procedure, including encoding and retrieval aspects of the task. They were then run on two experimental sessions, starting at about 2:00 p.m., on 2 separate, nonconsecutive days. Prior to the experiment, an intravenous (IV) needle was inserted into a forearm vein and attached to a $10-\mathrm{ft}$ polyethylene tube that extended out of the subject's room. A continuous normal (.9\%) saline drip was maintained throughout the experiment at the rate of $.5 \mathrm{ml} / \mathrm{min}$. 
All drug infusions were administered from outside the subject's room. Neither the subject nor the person administering the tests was aware of the time or whether drug or placebo was to be administered.

Subjects were pretreated with methscopolamine $(.3 \mathrm{mg} \mathrm{IV})$, which does not affect memory (Drachman \& Leavitt, 1974), to reduce possible peripheral effects of arecoline. Following this, subjects listened to one of two equivalent lists of nine groups of five words each. Three of the nine groups were made up of highly related (associated) words, as defined by their associative strengths, determined by Palermo and Jenkins (1964) norms. Three groups of five words were made up of weakly related items drawn from equivalent associative clusters. Three groups of five words, in each of the two lists, were made up of random words of equivalent imagery value and word frequency, based on Paivio, Yuille, and Madigan (1968) norms. Subjects listened to the words, presented in groups of five words each, and read at the rate of one word every $3 \mathrm{sec}$. They were then asked to think of and to say a word that might "define" or "organize" the word cluster $(10 \mathrm{sec})$. Subjects were also instructed, and were previously practiced, to generate words that might later serve as cues or prompts when attempting to remember the sets of words. The nine clusters of words were presented in the following order: A highly organized cluster always appeared first, then a weakly defined cluster (in Position 2), then a random word cluster (Position 3), then another highly organized cluster, and so on. Immediately after listening to all of the sets of five words and generating a word label that would function as an organizing and encoding word after hearing each set, the subjects were treated either with placebo or arecoline. Arecoline was administered as a slow infusion ( $2 \mathrm{mg}$ in 20-cc saline solution over $20 \mathrm{~min}$ ), while placebo was administered as a $(20-c c)$ saline solution. Half the subjects were treated with arecoline first and treated with placebo in a second session, while the other half of the subjects were first treated with arecoline and then placebo. After a delay of $1 \mathrm{~h}$ after infusion was begun, the recall phase of the study was initiated. At this point in time, arecoline was known to have been metabolized, and it could no longer exert any effect on the subject. After free recall, the subjects were presented their self-generated word responses as cues, and they again attempted recall of the nine groups of five words.

\section{RESULTS}

Arecoline significantly affected the free recall and cued recall of all of the presented word sets. Highly structured words, words that had minimal relationships with each other, and random word sets were all better recalled following arecoline treatment than under conditions of placebo treatment [postprocessing $F(1,7)=7.8, p<.05]$. This was true when retrieval was measured by free recall or in the presence of subjectgenerated cues (see Figure 1). This effect was determined to be a significant increase in the total number of clusters of words that were recalled, where at least one exemplar from a cluster appeared in recall $[F(1,7)=13.6, p<.01]$. This finding is displayed in Figure 2. The number of words per recall cluster was not different for those conditions in which subjects were treated with arecoline, as compared to placebo infusion. While cued recall produced more complete retrieval than free recall $[F(1,7)=29.6, p<.001]$ and highly structured word sets were remembered better than either weakly related or random words

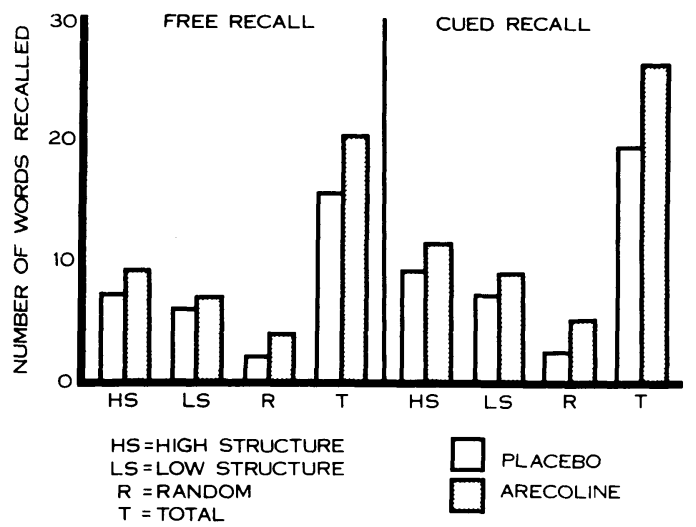

Figure 1. Recall of words following arecoline and placebo treatment.

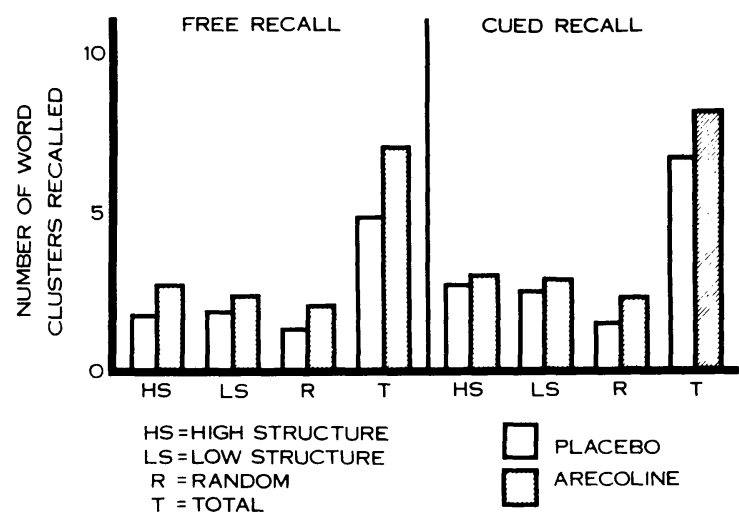

Figure 2. Recall of word clusters following arecoline and placebo treatment.

$[F(2,14)=31.6, p<.01]$, the facilitating effect of arecoline on learning and subsequent retrieval did not interact with these factors. The relationship between input serial position and probability of recall was also not altered by the drug treatment.

\section{DISCUSSION}

Characteristics of stimuli and methods of testing retrieval produced a predictable effect on word and category recall. For example, it is not surprising that highly structured material is recalled more effectively than are sets of random words. Likewise, one would expect that subjects attempting recall in the presence of powerful cues would recall more information than if remembering were to take place unaided (freely).

Recent studies have demonstrated that increasing cholinergic activity by pretreating subjects with either arecoline or physostigmine can enhance learning (Davis et al., 1971; Sitaram et al., 1978), while blocking cholinergic activity, for example, by treating subjects with scopolamine, can inhibit learning (Sitaram et al., 1978). In this study, we show that a drug manipulation that stimulates cholinergic functioning can facilitate the recall of categories of information and, thereby, word recall, and this can be accomplished by introducing the drug after words have been processed. This postlearning enhancement of memory consolidation by a drug that activates cholinergic neurons may, however, be dose dependent. Large doses of arecoline (5 $\mathrm{mg}$ IV in a rapid infusion) or physostigmine 
( $2 \mathrm{mg}$ IV bolus) may actually produce decrements in learning and memory. Presumably, at the time of drug treatment past learning, there exists a temporary trace of events in some memory representation. In this sense, low doses of arecoline given over $1 \mathrm{~h}$, through arecoline's effects on cholinergic functioning, seem to facilitate the consolidation of information in memory. Its action seems to be like other agents that seem to enhance or block memory consolidation in animal studies where a drug is introduced postlearning, rather than prior to or just at the time that learning takes place.

The finding that arecoline affects total word recall by affecting the number of categories that can be recalled, rather than the number of items per category, would suggest that the primary cognitive mode of action is to enhance memory consolidation by facilitating the formation of more salient memory structures or encoded organized engram structures that are more memorable at the time of retrieval, rather than through a facilitation of individual items within those structures. There are obviously other ways in which drugs might act to enhance learning. Research efforts directed at exploring how drugs, with known action sites in brain, might alter components of cognitive processes will provide a framework for defining a psychobiology of cognition.

\section{REFERENCES}

Alpern, H. P., \& Jackson, J. J. Short term memory: A neuropharmacologically distinct process. Behavioral Biology, 1978, 22, 133-146.

Caine, E. D., Ebert, M. H., \& Weingartner, H. An outline for the analyses of dementia. Neurology, 1977, 27, 1087-1092.

Davis, J. W., Thomas, R.'K., JR., \& ADams, H. E. Interactions of scopolamine and physostigmine with ECS and one trial learning. Physiology \& Behavior, 1971, 6, 219-222.

DEuTsCH, J. A. The cholinergic synapse and the site of memory. Science, 1971, 174, 783-794.

Drachman, D. A., \& LeavitT, J. Human memory and the cholinergic system. Archives of Neurology, 1974, 30, 113-121.

KhAVARI, K. A. Adrenergic-cholinergic involvement in modu- lation of learned behavior. Journal of Comparative and Physiological Psychology, 1971, 74, 284-291.

Matthies, R., Rauca, C., \& Liebmann, H. Changes in the acethycholine content of different brain regions of the rat during a learning experiment. Journal of Neurochemistry, 1974, 23, 1109-1113.

Moss, R., \& Deutsch, J. A. Review of cholinergic mechanisms and memory. In P. G. Waser (Ed.), Cholinergic mechanisms. New York: Raven Press, 1975.

Paivio, A., Yuille, J. C., \& Madigan, S. Concreteness, imagery and meaningfulness values for 925 nouns. Journal of Experimental Psychology Monograph, 1968, 76(1, Pt. 2).

Palermo, J. J., \& Jenkins, D. Palermo-Jenkins word associational norms: Grade school through college. Minnesota: Minneapolis Press, 1964.

Puerto, A., Molina, F., Rogers, J., \& Moss, D. F. Physostigmine-induced amnesia for an escape response 12 to 72 hours after training. Behavioral Biology, 1976, 16, 85-90.

Rose, S. P. R., Hambley, J., \& Haywood, J. Neurochemical approaches to developmental plasticity and learning. In M. R. Rosenzweig and E. L. Bennett (Eds.), Neural mechanisms of learning and memory. Cambridge, Mass: MIT Press, 1976.

Sitaram, N., Weingartner, H., \& Gillin, J. C. Human serial learning: Enhancement with arecoline and choline and impairment with scopolamine. Science, 1978, 201, 274-276.

SQUIRE, I. R. Physostigmine: Effects on retention at different times after brief training. Psychonomic Science, 1970, 19, 49-50.

Stanes, M. D., \& Brown, C. E. Effect of physostigmine on $y$-maze discrimination retention in the rat. Psychopharmacologia, 1976, 46, 269-276.

Stein, L., Belluzzi, J. D., \& Wise, C. D. Memory enhancement by central administration of norepinephrene. Brain Research, 1975, 34, 329-335.

Weingartner, H., Caine, E. D., \& Ebert, M. H. Imagery encoding and the retrieval of information from memory: Some specific-encoding-retrieval changes in Huntington's disease. Journal of Abnormal Psychology, in press.

(Received for publication September 12, 1978.) 